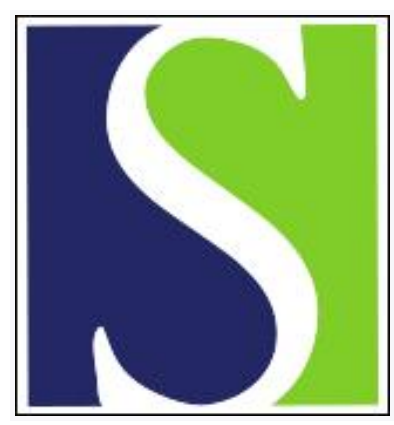

Scand J Work Environ Health 2019;45(2):101-102

https://doi.org/10.5271/sjweh.3807

Published online: 10 Feb 2019, Issue date: 01 Mar 2019

Prevention strategies for sickness absence: sick individuals or sick populations?

by Burdorf $A$

Affiliation: Department of Public Health, Erasmus Medical Center, Rotterdam, The Netherlands. a.burdorf@rasmusmc.nl

Refers to the following texts of the Journal: 2018;44(6):557-567

2018;44(3):274-282 2018;44(2):156-162 2018;44(2):192-201

2018;44(1):37-46

The following articles refer to this text: 2020;46(2):168-176;

2022;48(7):579-585

Key terms: editorial; prediction model; prevention; risk factor; sick individual; sick population; sickness absence

This article in PubMed: www.ncbi.nlm.nih.gov/pubmed/30739127

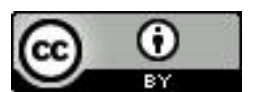




\section{Prevention strategies for sickness absence: sick individuals or sick populations?}

Sickness absence mesmerizes many researchers, given the numerous publications on risk factors for sickness absence. A large variety of risk factors have been identified, including work-related risk factors such as physical work demands and psychosocial work factors $(1,2)$, unhealthy behaviors such as lack pf physical activity and smoking $(3,4)$, and chronic health problems (5). A logical next step seems to be the development of a prediction model, whereby an individual's profile on risk factors is converted into a probability on future sickness absence. In the past few years, several prediction models have been developed and validated. It is in intriguing question how to use these models in occupational health practice to identify workers at risk for prolonged sickness absence reliably and to act on this.

The recent prediction models differ with respect to target populations, number, and type of predictors, and definition of sickness absence to be predicted. A large Finnish study among public sector employees with a 12year follow-up used 17 factors in a prediction model for short-term sickness absence ( $\geq 10$ days) and 14 predictors for long-term sickness absence ( $\geq 90$ days). The performance of the model, evaluated by the C-index (also known as the area under the curve), for short-term sickness absence was 0.65 and for long-term sickness absence 0.74 , representing poor-to-moderate model performance. For workers with higher risk levels, the positive predictive values were $<10 \%$, illustrating the poor predictive power of both models (6). Notenbomer and colleagues reported a similar poor performance (C-index 0.62 ) in their prediction model for long-term sickness absence during one year among workers with $\geq 3$ sickness absence episodes in the previous year (7). In both studies, prior sickness absence contributed modestly to the prediction models.

It may be argued that all-cause sickness absence is too crude a measure to predict, but prediction models for sickness absence due to specific causes have shown similar disappointing results. A Dutch study in the construction industry reported a $\mathrm{C}$-index of 0.65 for a prediction model with six predictor variables for any certified episode of low back pain sick leave during 1-year follow-up (8). Likewise, Hoffen and colleagues focused specifically on psychosocial work factors and sickness absence due to mental disorders. Their prediction model discriminated poorly (C-index 0.65 ) between workers with and those without long-term sick absence $>42$ days for mental health complaints during the 2-year follow-up (9). Shiri and colleagues developed a model with seven self-reported predictors for disability retirement due to musculoskeletal disorders during an 11-year follow-up in Finland. Although the overall performance of the model was promising with a $\mathrm{C}$-index of 0.82 , the rare occurrence of the outcome of interest resulted in a positive predictive value of about $14 \%$, illustrating that most workers who entered disability retirement due to musculoskeletal disorders were not identified (10).

Are prediction models for sickness absence the holy grail in occupational health? In theory, such models hold the promise to target individuals at risk and improve management of sickness absence by addressing risk factors. However, so far the models have shown disappointing results. Nevertheless, several authors seem optimistic that their prediction models are useful for prevention strategies. Even with a $\mathrm{C}$-index well below 0.70 , it is stated that "individual's risk can be estimated" (6), that "the model discriminated significantly between workers with frequent sickness absence and those without"(7), or that "the model's risk predictions were adequate" (8). Apart from the challenges to develop a valid prediction model, it appears that recent publications discuss too little whether the aim of the decision model should be to detect predictors and their relative importance or to deliver predictions for individuals at risk.

The important distinction between focus on predictors or prediction links directly to the potential usefulness of a prediction model in prevention strategies. The performance of recently developed models is certainly not good enough for selective prevention, whereby groups of individuals at risk of prolonged sickness absence or disability benefits can be identified and targeted for subsequent preventive actions. At best, these models 
illustrate the relative importance of various individual and work-related risk factors for sickness absence that may be targeted in prevention strategies. In essence, current models are much more informative for identifying predictors than for making predictions.

This conclusion raises the question whether prediction models for sickness absence can guide in the classical choice between selective prevention or universal prevention. It is almost 35 years since Geoffrey Rose eloquently phrased the notion that it is important to distinguish between individuals who are sick and sick populations. $\mathrm{He}$ argued that the choice for the best prevention strategy should be determined by the distribution of risk in the population: with an extreme distribution, the 'high-risk' approach - which seeks to protect susceptible individuals - is more beneficial, whereas, with a continuous distribution of risk, the population approach - which seeks to control the causes of disease - is more appropriate (11).

The recent prediction models on sickness absence have identified several risk factors that contribute to future sickness absence such as high physical work demands, and shift work. These risk factors are commonly present in occupational populations. Therefore, in line with Rose's notion, our main concern should be to discover and control the causes of sickness absence in the workforce.

\title{
References
}

1. Andersen LL, Thorsen SV, Flyvholm MA, Holtermann A. Long-term sickness absence from combined factors related to physical work demands: prospective cohort study. Eur J Public Health. 2018;28(5):824-29. https://doi.org/10.1093/eurpub/cky073

2. Aronsson V, Toivanen S, Leineweber C, Nyberg A. Can a poor psychosocial work environment and insufficient organizational resources explain the higher risk of ill-health and sickness absence in human service occupations? Evidence from a Swedish national cohort. Scand J Public Health 2018, Nov 29, epub ahead of print. https://doi.org/10.1177/1403494818812638

3. Kanerva N, Pietiläinen O, Lallukka T, Rahkonen O, Lahti J. Unhealthy lifestyle and sleep problems as risk factors for increased direct employers' cost of short-term sickness absence. Scand J Work Environ Health 2018; 44: 192-201. https://doi.org/10.5271/sjweh.3695

4. Virtanen M, Ervasti J, Head J, et al. Lifestyle factors and risk of sickness absence from work: a multicohort study. Lancet Public Health 2018;3: e545-54.https://doi.org/10.1016/S2468-2667(18)30201-9

5. Newington L, Stevens M, Warwick D, Adams J, Walker-Bone K. Sickness absence after carpal tunnel release: a systematic review of the literature. Scand J Work Environ Health 2018;44(6):557-67. https://doi.org/10.5271/sjweh.3762

6. Airaksinen J, Jokela M, Virtanen M, Oksanen T, Koskenvuo M, Pentti J, et al. Prediction of long-term absence due to sickness in employees: development and validation of a multifactorial risk score in two cohort studies. Scand J Work Environ Health 2018;44(3):27482. https://doi.org/10.5271/sjweh.3713

7. Notenbomer A, rhenen van W, Groothoff JW, Roelen CAM. Predicting long-term sickness absence among employees with frequent sickness absence. Int Arch Occup Environ Health 2018, Nov 24, epub ahead of print. https://doi.org/10.1007/s00420-018-1384-6

8. Bosman LC, Dijkstra L, Joling CI, Heymans MW, Twisk JWR, Roelen CAM. Prediction models to identify workers at risk of sick leave due to low-back pain in the Dutch construction industry. Scand J Work Environ Health 2018;44(2):156-62. https://doi.org/10.5271/ sjweh.3703

9. Hoffen van MFA, Roelen CAM, Rhenen van W, Schaufeli WB, Heymans MW, Twisk JWR. Psychosocial work characteristics and long-term sickness absence due to mental disorders. J Mental Health, 2018, Feb 9, epub ahead of print. https://doi.org/10.1080/09638 237.2018.1437603

10. Shiri R, Heliövaara M, Ahola K, Kaila-Kangas L, Haukka E, Kausto J, et al. A screening tool for the risk of disability retirement due to musculoskeletal disorders. Scand J Work Environ Health 2018;44(1):37-46. https://doi.org/10.5271/sjweh.3684

11. Rose G. Sick individuals and sick populations. Int J Epidemiol 1985;14:32-8. https://doi.org/10.1093/ije/14.1.32

\author{
Alex Burdorf \\ Department of Public Health \\ Erasmus Medical Center \\ Rotterdam, The Netherlands \\ [Email:a.burdorf@rasmusmc.nl]
}

